\title{
Multi-criteria analysis of UAVs regulations in 6 countries using the analytical hierarchical process and expert knowledge
}

\author{
A.C.Morales, D. Paez, C.Arango \\ Universidad de los Andes, Colombia
}

KEY WORDS: UAVs, regulation, international UAV experiences, Multi-criteria analysis, Analytical hierarchical process

\begin{abstract}
To analyze the current situation of Colombian regulation, it is necessary to compare some specific aspects with the legislation used in other countries where the UAVs topic dates to many years ago. This study is focused on evaluating all the possibilities to make the Colombian regulation effective without closing opportunities of research and development growth, but still guarantee the privacy and intimacy rights of the population.

Results from our study are currently being used in the development of the Colombian regulation and they are proven useful to instigate informative debates and identify areas where specific needs are to be address in Colombia.
\end{abstract}

\section{Introduction}

The popularization of UAVs application has created an increased debate within society in relation to the need to regulate their use. In particular, two main concerns are appearing to be dominant as main points to be addressed by regulations: privacy and air safety.

In Colombia and in many other countries, regulations are being draft for approval by governments and parliaments. In this process, the need to understand effectiveness and efficiency of regulations in other nations is fundamental. For example, UAVs regulations in Australia were developed and approved over 15 years ago, creating an opportunity to assess their performance to address community concerns and at the same time support the sustainable development of the country.

In this paper we present and assessment framework for UAV regulations. It is based on a multi-criteria analysis that considers three main factors: limitations to research and development, business and community integration and air safety and community protection.

Using an Analytical Hierarchical process and with the participation of over 20 international experts the multi-criteria framework was used to first compare and then evaluate current and future proposed regulations in 6 countries: USA, United Kingdom, Canada, Australia, France and Spain. 
As a result, and disaggregated for specific sections of regulations comparable for the 6 countries, rankings in each of the factors were produced in where regulations could be assessed.

In general terms, most regulations score high in relation to air safety while limited sections of them address privacy concerns. It was also notorious in our analysis and results that significant limitations imposed in some jurisdiction to commercialization of the technology (for example Australia) while in other is widely promoted (France).

Future research opportunities are in comparing what has been the actual effect of regulations in air safety and the use of civilian UAVs in the development of society. For this, factors such as accidents and the number of equipment sold are options to be considered.

\section{UAVs Regulation around 6 different countries}

\subsection{Australia}

Around 2002 in anticipation of civil operations of UAVS, stared a project called "Project OS 11/20- Review of Regulations and Guidance Material Relating to Unmanned Aircraft Systems (UAVS)", which included with limited detail a basis for the CASA (Civil Aviation Safety Authority) to implement and attend over the Industry. On this basis, there were some regulations about the required pilot qualification, risk management, airworthiness operational approval processes, among others.

\section{( Australian Government)}

The project objective is to update the regulation where is considered the long term integration of the UAVS into normal aviation operations in all classes of airspace. At the time this project was on process, there was already a document called "CASR Part 101" which contains all the rules for Unmanned Aircraft Systems up to 2002. With the Project OS11/20 the integration of new technologies was taking part on the new regulations, and so, the project was undertaken in two phases. The Phase 1 was focused on the adjustment of the CASR Part 101 making an extension of these rules affecting not only the industry, but the organizations or individuals involved in unmanned balloons (including significant numbers of party balloons) and rocket operations, organizers of firework displays, model aircraft owners and operators, research and development organizations, law enforcement agencies, surveillance organizations, weather research organizations and potential users of airborne telecommunications systems. The Phase 2, was a complete re-write of the regulation and attaches it all in a new document called "CASR Part 102".

All this continuous process since 2002, makes of Australia one of the most advanced countries in terms of UAVS legislation now a days. (Civil Aviation Safety Authority of Australia) 


\subsection{United States of America}

The FAA (Federal Aviation Administration) is the authority uncharged of controlling the national airspace. In USA, introducing the UAVS is challenging because this country has the busiest airspace in the world. For this reason they are taking an approach to its integration from three different situations.

The first one relates to the public operations, which refers to common public uses like disaster relief, search and rescue, military training between other government operational missions. All these operations are made through specific agencies approved by the government and they must be registered at the Certificate of Authorization online system. The approval process is completed within 60 business days and all the information about those agencies is required. This standards where stablished by the FAA on 2014 on the advisory circular 00-1 of Public Aircraft Operations. (Federal Aviation Administration)

The second situation involves all the civil operations which are Non-Governmental operations or at least any operation that does not belong to the public aircraft operations described above. In this case, the FAA still needs to give an authorization for civil flights and it is mainly gained by two methods. The Section 333 of the FAA Modernization and Reform Act of 2012 gives the Secretary of Transportation the power to determine whether an airworthiness certificate is required to operate safely, so they analyze case by case in order to avoid the use of UAVS for commercial purposes. On the other hand, there is a Special Airworthiness Certificate (SAC) where the applicants must give information to de FAA about how the aircraft is designed including engineering processes, its software development and finally how and where they intend to fly. (Federal Aviation Administration)

Finally the third group relates to all the hobby or recreation activities only. For this case, the FAA and several industry associations are promoting an educative campaign to teach the public how to use unmanned aircraft safely and responsibly. The main safety guidelines are to fly below 400 feet and remain clear of surrounding obstacles, keep the aircraft within visual line of sight at all times, do not interfere with manned aircraft operations, do not fly within 5 miles of an airport, do not fly near people or stadiums and the aircraft must weight less than 55 lbs. (Federal Aviation Administration)

\subsection{France}

This country is recognized for its strict regulation; it means there are no exceptions when it comes to ask for permission. The DGCA (Directorate General of Civil Aviation) classified UVS into 7 categories depending on the characteristics of the aircraft. Those categories are named form the A to de $G$ giving different limitations of weight, systems of propulsion and accessories that must contain. 
On the other hand, the DGCA describes 4 different scenarios where the UAVS can be flown.

Scenario 1, which represents the operations taking place outside populated areas in direct sight of pilot, with a maximum horizontal distance of 100 meters from him.

Scenario 2, also in places outside of the populated area flying less than 50 meters above the surface or obstacle and 1 kilometer radius.

Scenario 3, contrary to the last 2 scenarios, these operations take place in urban areas but still in direct view of the pilot at a maximum horizontal distance of 100 meters. And finally, the scenario 4 involves the activity of taking photographs or recording during a flight of less than 150 meters height. (Civic Drone)

All this regulation was developed on 2012 by the ministry of Transport's Civil Aviation Authority and covers all UAVS. Its omission conveys to criminal sanctions. (Civic Drone)

\subsection{Canada}

As it is sanctioned in France, Canada is the responsible to fly the aircraft legally and safely. Canada government has its own authorization system where in some scenarios it is not necessary to have permission. Despite this, in every flight pilot must follow do and do not program which means following the "Canadian Aviation Regulations" respecting the criminal code and laws related to privacy. It is prohibited to fly closer than 9 kilometers from any airport or higher than 90 meters above the surface or closer than 150 form population.

In Canada, there are three situations where the pilot must apply for a special flight operation certificate. When the aircraft weights more than 35 kilograms and it is not for research; when the flight has investigation purpose and weights more than 25 grams or less than 2 kilograms; and finally when the mission cannot meet any exemption requirements stipulated by the Canadian government. (Government of Canada)

The government, thrust their citizens will act according their regulation and applying to permission in case it is required. That is the reason why they have only two exemption requirements guide which must be followed when there is not permission necessary, and the flight safely guide. (Transport Canada)

\subsection{Spain}

Now days the UAVS use is limited to unpopulated areas and uncontrolled airspace. The authorized activities in which drones can be used are for research and development, spreading substances in the soil, emergency and rescue operations and other special works. It is prohibited the video recording except when it is taken in closed rooms including the ceiling. The reason why it is possible to take video or photographs inside a building is because it is not under the jurisdiction of the EASA (European Aviation Safety Agency). 
The maximum distance from the pilot approved to fly are 500 meters with direct sight, a weight less than 25 kilograms and 120 meters above the surface. Every aircraft with more than 25 kilograms of weight has to apply for the EASA permission and those that weight 25 kilograms or less must fulfill three main standards: Nameplane, Authorized pilot and operate in areas not populated and uncontrolled airspace.

To take photographs or videos outdoors it is necessary to achieve qualification as operator of drones taking some required documents to the EASA and proving the capacities acquired to be a drone pilot. It means that in any type of aircraft, manned or not, it is necessary to obtain specific authorization from EASA for such activity.

\subsection{United Kingdom}

The civil aviation authority (CAA) has the specific task of controlling the UAVs use along the entire area. As most of the previous countries analyzed, the UK takes as a priority the safety of its population. That is the reason why the main requirement is that the aircraft operation must not endanger anyone or anything. Now days, the UAVs legislation is denoted by the air navigation order, where every case is fully described. (Civil Aviation Authority of the UK)

Keeping the aircrafts under the visual line of sight and not taking pictures or any material that could affect the privacy of anyone, are some of the main restrictions of this normative. In comparison with the other countries described, the UK is more specific in the regulation redaction. For example, it is clear that the urban or population centers are those which have more than 1000 people, or that the only exception where the UAV is allowed to be within the 50 meters of a person is during the take-off or landing.

\section{Outlook}

The Colombian regulation is now a days getting up to date taking into account the UAVs technologies development, trying to find the balance to guarantee the intimacy and privacy to the civil population, and the incorporation of the aircrafts even for recreation. Through all this process, is the International Civil Aviation Organization (ICAO) the authority uncharged of regulating and giving the permissions in every case if it is required.

In contrast with the legislation in the other countries analyzed in this document, Colombia does not have any stablished law yet. Despite this, there are some prohibitions and standards that must be followed to fly any UAVs while the required normative is published. In Colombia the restriction items like in all six countries described, are mainly based on weight control, energy source and places where is allowed to fly. Most maximum values are similar to Canada or France regulation in terms of the three standards just named. 
While the law where UAVs are comprehended is stablished, the state is acting with a high level of precaution leading to many prohibitions.

Due to the poor classification of the UAVs that now days is being used in Colombia, it is not allowed: To have a takeoff weight over the 25 kilograms, the flight must be realized only with daylight, away from population centers, good weather conditions which allows the pilot have a constant sight of the aircraft, and finally the UAV must fulfill certain characteristics of shape to be flown.

In the other hand, there is a similar concept of the restrictions that are enforced in terms of any other use different from recreation. It is considered to implement a certification system where all the interested institutions or people must apply to get the authorization to fly every time it is required. This procedure is already implemented by the United States government through the certificate of Authorization Online System where selected agencies are inscribed to work hand in hand with the government, and the Special Airworthiness Certificate (SAC) where the applicants must give information to de FAA about how the aircraft design, its software development and finally how and where they intend to fly.

At the moment the Colombian government still does not have the criteria or the necessary information to develop its own system as it is planned. It conduces to have the current situation in similar circumstances as the Canadian law is set. Under this condition, the government is forced to believe in the right procedure of its civil population to start the authorization process when needed as stipulated. The reason for this situation is the limited capacity of the government to verify that every UAV flying over the Colombian territory meets the requirements.

While the commercial field of these aircrafts is growing, in Colombia the current and conservative legislation tries to cover up every possible situation under which the UAVs are used. Probably this commercial field is not as developed as in many other countries, which is an advantage during the process of the long term law, but at present the government is not including any educational program to involve the community and teach them the right and safe way to fly an UAV. This kind of program is truly successful in countries like the United States and Canada and should be taken into account even with more magnitude under the current Colombian situation as a starting point

\section{Summary}

Based in the other countries regulation this analytical hierarchical process give us information to decide it is not just a regulation, there are more native things to take care about between people and regulation restriction, It is not just force a restriction, it's make a teaching process, where the important is do balance over government, academic and civilian operation (business and hobbies). 
The best form to still keep safe the air space is establish normative but its most important create course or training program according to people behavior for each country. In the other hand, other important issues is the government give financial support to training academic make all programs reachable all operator.

\section{References}

Australian Government(s.f.), Aeronautical information management. 12_June_2015. http://www.casa.gov.au/scripts/nc.dll?W CMS:PWA::pc=PC_100532

Civic Drone(s.f.) Regulatory News. 12_June_ 2015. http://www.civicdrone.com/news/regulato ry-news-about-uav-in-france-c10027.html

Civil Aviation Authority of the UK. (s.f.). Drone Flight. 18_June_2014, Reach for the Sky: http://droneflight.co.uk/pages/summaryof-uk-legal-requirements

Civil Aviation Safety Authority of Australia(s.f.). Advisory Cicular AC 1011 (0). 14_June_2015, http://www.casa.gov.au/wcmswr/_assets/ main/rules/1998casr/101/101c01.pdf

Federal Aviation Administration (s.f.)

Civil Operations. 12_June_2015.

https://www.faa.gov/uas/civil_operations/

Federal Aviation Administration. (s.f.).

Federal Aviation Administration.
12_June_2015. Public Operations. https://www.faa.gov/uas/public_operation Federal Aviation Administration. (s.f.). Model Aircraft Operations. 12_June_ 2015.

https://www.faa.gov/uas/model_aircraft/

Government of Canada. (s.f.). Flying an unmanned aircraft recreationally.

12_June_2015.

http://www.tc.gc.ca/eng/civilaviation/stan dards/general-recavi-uav-2265.htm

?WT.mc_id=1zfhj\#safety

Transport Canada. (s.f.). Flying an Unmanned Aircraft. 12_June_ 2015. http://www.tc.gc.ca/media/documents/castandards/Infographic_Permission_to_fly _a_UAV_Print_English.pdf 